\title{
Polymorphism of XRCC1 Gene Exon 6 (Arg194Trp) in Relation to Micronucleus Frequencies in Hospital Radiation Workers
}

\author{
H.N.E. Surniyantoro*1, Y. Lusiyanti ${ }^{1}$, T. Rahardjo ${ }^{1}$, D. Tetriana ${ }^{1}$, \\ S. Nurhayati ${ }^{1}$ and $H$. Date ${ }^{2}$ \\ ${ }^{1}$ Center for Radiation Safety Technology and Metrology, National Nuclear Energy Agency \\ Jl. Lebak Bulus Raya No. 49, Jakarta 12440, Indonesia \\ ${ }^{2}$ Faculty of Health Sciences, Hokkaido University, Kita-12, Nishi-5, Kitaku, Sapporo 060-0812, Japan
}

\section{ARTICLE INFO}

\section{Article history:}

Received 11 November 2017

Received in revised form 17 July 2018

Accepted 18 July 2018

\section{Keywords:}

Genetic polymorphism

DNA repair gene

XRCC1 exon 6

Micronucleus

Ionizing radiation

Radiation workers

\begin{abstract}
A B S T R A C T
The genetic polymorphism of deoxyribonucleic acid (DNA) repair genes plays important roles in regulating individual sensitivity to ionizing radiation, maintaining DNA integrity, and preventing cancer and DNA damage. X-ray repair crosscomplementary group 1 (XRCC1) as one of the members of base excision repair (BER) is involved in the repairement of oxidized bases and single-strand breaks DNA after exposure by reactive oxygen species (ROS), including ionizing radiation. This study aimed to examine the correlation between XRCC1 exon 6 gene polymorphism and micronucleus ( $\mathrm{MN}$ ) frequency in radiation workers and their relation to age, gender, smoking status and years of exposure. This study involved 81 hospital radiation workers and 20 controls from several hospitals in Indonesia. Genotyping of XRCC1 exon 6 gene polymorphism and MN assay were performed using polymerase chain reaction-restriction fragment length polymorphism (PCR-RFLP) and cytokinesis-block micronucleus assay (CBMN assay), respectively. The results indicated that $\mathrm{MN}$ frequency was significantly higher in the exposed workers than in the controls $(15.38 \pm 7.72$ versus $9 \pm 5.49 ; p=0.001)$. Radiation workers with heterozygous alleles for XRCC1 polymorphisms showed a significantly higher $\mathrm{MN}$ frequency than controls with the same genotypes $(17.5 \pm 8.36$ versus $7.44 \pm 5.05 ; p=0.002)$. The confounding factors, like gender and age, were significantly associated with increased MN frequency both in radiation workers and controls. Smoking status was significantly associated with MN frequency in the controls only, while years of exposure did not affect MN frequency either in radiation workers or controls. These results suggest that the genetic polymorphism of XRCC1 gene exon 6 with a mutant heterozygous/cytosine-thymine (CT) variant demonstrated an association with the extent of DNA damage in the hospital radiation workers in this study. In the subsequent studies, it will be necessary to examine the DNA repair genes polymorphism in populations with controlled non-genetic factors, such as lifestyle, environment, and exercise, that affect the MN frequency as a biomarker of DNA damage.
\end{abstract}

(C) 2018 Atom Indonesia. All rights reserved

\section{INTRODUCTION}

The effects of radiation, both deterministic and stochastic, on the human system depend on the degree of radiosensitivity of different body tissues. The most sensitive tissues are generally the largest

${ }^{*}$ Corresponding author

E-mail address: harry_nes@batan.go.id DOI: https://doi.org/10.17146/aij.2018.770 constituent components in the form of fluids, blood, and red bone marrow. The human body consists of liquids (60\% of the body weight) and blood ( $8 \%$ of body weight, where for women this figure is slightly lower). The blood consists of approximately $45 \%$ blood cells (erythrocytes or red blood, leukocytes or white blood, and thrombocytes or freezers) and approximately $55 \%$ blood plasma. White blood cells or leukocytes have a sufficiently high 
sensitivity to radiation such as fetal body cells and certain cancer cells [1].

In recent decades, some biomarkers such as cytogenetic analyzes have developed very rapidly, especially in terms of detection of damage caused by ionizing radiation. Chromosome aberration is one way to evaluate the damage caused by ionizing radiation in humans. The micronucleus (MN) technique has been proposed as a method for measurement of chromosomal damage in mitogenstimulated human lymphocytes [2]. MN is composed of asymmetric chromosome fragments or intact chromosomes that are not distributed to the main nucleus during the process of anaphase. This is due to several factors, one of which is ionizing radiation [3]. This MN measurement method can be used in populations exposed to ionizing radiation or populations living in areas with high background radioactivity [4].

MN formation process is very complex. Ionizing radiation interacts with cells and causes damaging effects especially in cellular DNA. DNA repair enzymes in cells will prevent damage caused by ionizing radiation. Several types of DNA repair enzymes such as XRCC1, XRCC3, and XPD play a role in maintaining the structural integrity of DNA and preventing cellular DNA damage [5]. XRCC1 protein forms a complex consisting of DNA polymerase beta, DNA ligase III, and poly-ADPribose polymerase (PARP) and have a role in repairing the DNA damage. It is located on chromosome 19q13.2-13.3 with a length of 33 kilobases. Polymorphism of XRCC1 codon 194 in exon 6 results in an arginine (Arg) to tryptophan (Trp) substitution. This amino acid substitution has been associated with a decreased ability to repair DNA damage in vitro [6]. A strong association between the XRCC1 codon 280 variant allele and increased risk of lung cancer has been described [7], and XRCC1 codon 399 variant allele appeared to be a risk factor for head and neck cancer, adenocarcinoma of the lungs [8], and breast cancer (in African Americans but not in Caucasians) [9]. In one study, XRCC1 codon 194 and 399 variant alleles were found to be protective towards bladder cancer [10].

Since radiation therapy exerts its cytotoxic effects through damage to cells, proteins, and DNA, the individual capacity to repair damaged DNA may modify the response of the normal tissue. The individual DNA repair capacity consists of several pathways: nucleotide and base excision repair (BER) pathway, homologous recombination, end joining, mismatch repair, and telomere metabolism. BER of single-strand breaks as well as non-homologous end joining and homologous repair of double-strand breaks are considered the most important pathways involved in repair of radiationinduced DNA damage. The protein acts as a scaffold to coordinate other BER proteins at the repair site [11]. Cells defective in XRCC1 have an increased sensitivity to ionizing radiation, UV, hydrogen peroxide, and mitomycin [12].

XRCC1 on BER pathway plays an important role to remove damaged DNA. Glycosylases catalyze the DNA fragments and $\mathrm{N}$-glycosidic bonds that will effectively remove DNA that has been cut by endonuclease DNA enzymes and will form apurinic or apyridinic sites (AP sites). Polymorphisms in XRCC1 exon 6 will reduce the ability to repair DNA and are reported to be associated with cancer risk and treatment response (Fig. 1) [13]. This study was aimed to examine the correlation between XRCC1 exon 6 gene polymorphisms and $\mathrm{MN}$ frequency in radiation workers and their relation to age, gender, smoking status, and years of exposure.

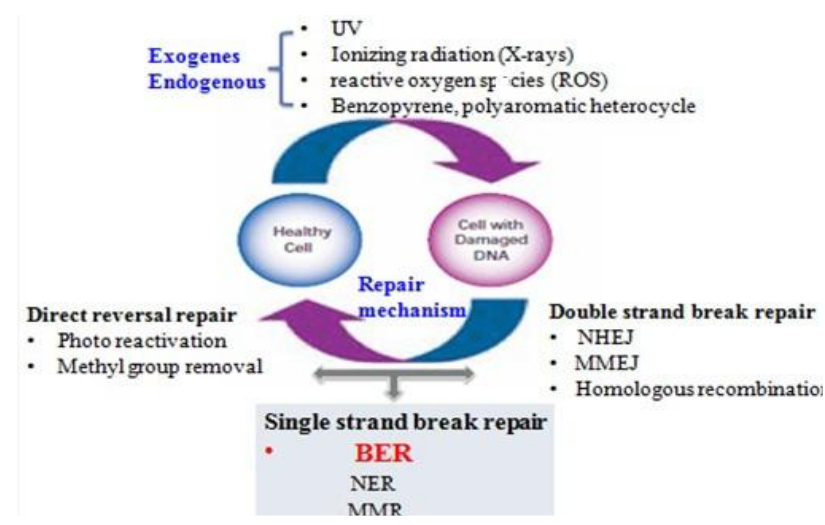

Fig. 1. Several pathways of DNA repair systems in cell exposed to exogenous and endogenous agents [13].

\section{EXPERIMENTAL METHODS}

\section{Study population}

The subject of this study were 81 medical workers occupationally exposed to low doses of ionizing radiation (IR) in the Unit of Radiology and Radiotherapy at Gatot Subroto, Kariadi and Otak (Brain) Hospitals, Indonesia, and 20 controls who had never been occupationally exposed to IR or other known carcinogenic agents. All of the subjects gave their written consent after being informed of the study scope and experimental details. Standardized questionnaires were administered to all of the participants to determine their sociodemographic characteristics, medical history (e.g., history of medical treatments, radiography, recent vaccination, severe infections or viral diseases over the past six months, presence of known inherited genetic disorders and chronic 
diseases, family history of cancer), age, gender, smoking status, years of exposure, and equivalent dose (mSv). Exclusion criteria included the use of any therapeutic drugs, radiotherapy, and diagnostic $\mathrm{X}$-rays undergone within 12 months prior to sampling which could have significantly contributed to the received dose and/or genetic damage. Selected demographic characteristics of the study population are reported in Table 1. Among the medical workers, we distinguished between four different working tasks: doctors, radiologists, radiotherapists, and nurses. Each participant was briefed about the study protocol, with specific written information about the cytogenetic test and the aims of the study; the participant then signed an informed consent. Venous blood was obtained from each subject and transferred to the laboratory within a few hours for subsequent CBMN assay and genotype analysis.

Table 1. Demographic characteristics of the study population

\begin{tabular}{lccc}
\hline & Exposed & Controls & Total \\
\hline Sampel size (n) & 81 & 20 & 101 \\
Gender & & & \\
Females (\%) & $32(39.5)$ & $10(50)$ & $42(41.58)$ \\
Males (\%) & $49(60.5$ & $10(50)$ & $59(58.42)$ \\
Age (years) & & & \\
Mean \pm SD & $42.48 \pm 10.01$ & $39.25 \pm 12.3$ & $41.84 \pm 10.51$ \\
Range & $24-71$ & $20-54$ & $20-71$ \\
Smoking status & & & \\
Never (\%) & $72(88.9)$ & $12(60)$ & $84(83.17)$ \\
Current $(\%)$ & $9(11.1)$ & $8(40)$ & $17(16.83)$ \\
Years of exposure & & & \\
$\quad$ Mean \pm SD & $14.30 \pm 10.88$ & - & - \\
Range & $1-37$ & & \\
\hline
\end{tabular}

\section{Micronuclei assay}

The CBMN- assay was performed as described by Fenech (2007) [3] with some modifications. Lymphocyte cultures were incubated for $48 \mathrm{~h}$ at $37^{\circ} \mathrm{C}$. Cytochalasin-B (Sigma-Aldrich) at a final concentration of $3 \mathrm{~g} / \mathrm{mL}$ was added to cultures to block cytokinesis after $44 \mathrm{~h}$ of incubation. The cultures were stopped at $72 \mathrm{~h}$, treated with a hypotonic solution for 4 minutes and fixed with two changes of methanol:acetic acid $(3: 1, \mathrm{v} / \mathrm{v})$. The fixed cells were spread onto clean glass slides and stained for 10 min with a $4 \%$ Giemsa solution. All slides were coded. Microscopic analysis was performed under a light microscope with a $40 \times 10$ magnification, and CBMN- assay parameters of $\mathrm{MN}$ was verified under $1000 \times$ magnification. Scores were obtained for slides from each subject. The frequency of binucleated $(\mathrm{BN})$ cells containing one or more MN was scored in 1000 cells per subject, in order to determine cytotoxicity in accordance with published CBMN-Cyt scoring-criteria refers to IAEA manual [3].

\section{DNA isolation}

DNA was isolated from lymphocytes extracted from whole blood using the QIAamp DNA Kit (Qiagen) according to the manufacturer's instructions. The obtained DNA was stored at $-20{ }^{\circ} \mathrm{C}$ until used.

\section{Genotyping of XRCC1 exon 6 single- nucleotide polymorphisms (SNPs)}

Genotyping of XRCC1 exon 6 gene polymorphisms was performed using polymerase chain reaction-restriction fragment length polymorphism (PCR-RFLP) as described previously by Ryu et al. [14] with modifycation. The forward primer was 5'GCCCCGTCCCAGGTA-3' and the reverse primer was 5'-AGCCCCAAGACCCTTTCACT-3'. The PCR reactions were carried out with an initial denaturation at $95{ }^{\circ} \mathrm{C}$ for $2 \mathrm{~min}$, followed by 35 cycles at $94{ }^{\circ} \mathrm{C}$ (denaturation) for $30 \mathrm{~s}, 60^{\circ} \mathrm{C}$ (annealing) for $30 \mathrm{~s}$ and $72{ }^{\circ} \mathrm{C}$ (extension) for $45 \mathrm{~s}$, and, finally, $72{ }^{\circ} \mathrm{C}$ (final extension) for $5 \mathrm{~min}$. Following amplification, PCR products were digested using $10 \mathrm{U}$ of $M s p \mathrm{I}$ restriction enzyme (BioLabs, Inc.) at $37{ }^{\circ} \mathrm{C}$ for $16 \mathrm{~h}$, and electrophoresed on a $3 \%$ agarose gel and stained with ethidium bromide. The wild-type CC genotype for codon 194 was determined by the presence of two bands at 292 and $174 \mathrm{bp}$, the mutant heterozygous CT genotype was determined by the presence of three bands at 313, 292 and $174 \mathrm{bp}$, while the mutant homozygous TT genotype was determined by the presence of 313 and 174 bp bands.

\section{Statistical analysis}

The statistical analysis of the data was conducted with SPSS version 16.0 for Windows. Data were expressed as mean \pm SD. Mann-Whitney $\mathrm{U}$ test was used to test $\mathrm{MN}$ frequency difference between exposed workers and control and to test a significant relationship between $\mathrm{MN}$ and various genotypes. Linear regression analysis was performed to assess the relationship between years of exposure and MN frequency on exposed workers. Poisson regression analysis was applied to evaluate the influence of age, sex, smoking status, and years of exposure to ionizing radiation at $\mathrm{MN}$ frequencies in the whole population and in both groups separately. The genotype and allele frequencies were showed on frequencies distribution table and were checked for consistency with Hardy-Weinberg equilibrium and compared between the radiation workers and controls group by $\chi^{2}$ tests. The level of significance was set at $p<0.05$. 


\section{RESULTS AND DISCUSSION}

\section{MN analysis}

Micronuclei test results were reported as total number of $\mathrm{MN}$ per $1000 \mathrm{BN}$ and presented in Table 2. MN frequency was significantly higher in hospital radiation workers compared to control $(15.38 \pm 7.72 \quad$ versus $9 \pm 5.49, \quad p=0.001)$. The frequency of $\mathrm{MN}$ in the non-smokers group was higher than in the smokers group, both in radiation workers $(15.58 \pm 7.68$ versus $13.78 \pm 8.32)$ and controls $(10.33 \pm 6.2$ versus $7 \pm 3.7)$, although the difference was significant only when comparing the non-smokers in radiation workers group with the non-smoking controls $(15.58 \pm 7.68$ versus $10.33 \pm 6.2 ; p=0.024)$. Number of years of exposure for radiation workers were 1-37 years with an average working period of $14.30 \pm 10.88$ (Table 1). Linear regression analysis was performed to examine the effect of years of exposure to $\mathrm{MN}$ frequencies. No significant relationship was found between years of exposure and $\mathrm{MN}$ frequency $(\beta=0.045, p=0.689 ;$ Fig. 2$)$.

Table 2. MN frequencies in the study population

\begin{tabular}{lcccccc}
\hline & \multicolumn{3}{c}{ Radiation workers } & \multicolumn{3}{c}{ Controls } \\
\cline { 2 - 7 } & Subjects & $\begin{array}{c}\text { MN/1000 BN } \\
\text { mean } \pm \text { SD }\end{array}$ & $95 \%$ CI & Subjects & $\begin{array}{c}\text { MN/1000 BN } \\
\text { mean } \pm \text { SD }\end{array}$ & $95 \%$ CI \\
\hline All & 81 & $15.38 \pm 7.72^{\mathrm{a}}$ & $13.69-17.06$ & 20 & $9 \pm 5.49$ & $6.59-11.41$ \\
Never smokers & 72 & $15.58 \pm 7.68^{\mathrm{b}}$ & $13.81-17.35$ & 12 & $10.33 \pm 6.2$ & $6.82-13.84$ \\
Current smokers & 9 & $13.78 \pm 8.32$ & $8.34-19.21$ & 8 & $7 \pm 3.7$ & $4.44-9.56$ \\
XRCC1 exon 6 & & & & & & \\
CC & 37 & $13 \pm 7.03$ & $10.73-15.26$ & 9 & $11.33 \pm 5.38$ & $7.82-14.84$ \\
CT & 26 & $17.5 \pm 8.36^{\circ}$ & $14.29-20.71$ & 9 & $7.44 \pm 5.05$ & $4.14-10.74$ \\
TT & 18 & $17.22 \pm 7.08$ & $13.95-20.49$ & 2 & $5.5 \pm 6.36$ & $-3.31-14.31$ \\
\hline
\end{tabular}

$\mathrm{BN}$, binucleated cells.

a Significantly different from total controls (Mann-Whitney U test, $p=0.001)$.

b Significantly different from controls with the same habit (never smokers) ( Mann-Whitney U test, $p=0.024$ ).

c Significantly different from controls with the same genotype (MannWhitney U test, $p=0.002$ )

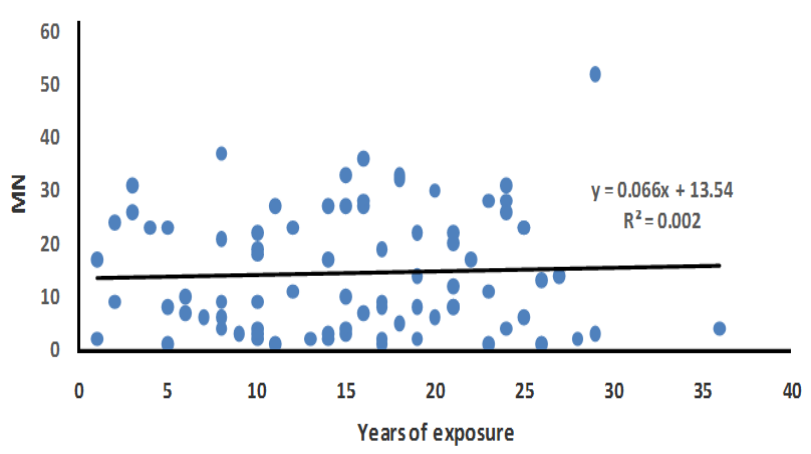

Fig. 2. The relationship between DNA damage, assessed as MN frequency in peripheral lymphocytes, and years of exposure to ionizing radiation. The thick line is the result of linear regression analysis of the data. $\beta=0.045, p=0.689$.
Poisson regression results on gender, age, and smoking status are shown in Table 3. Gender and age factors have a significant effect on $\mathrm{MN}$ frequencies in both radiation workers and control $(p<0.0001)$. The mean of $\mathrm{MN}$ frequencies in females was higher than in males. The smoking status factor significantly influenced the MN frequency only in control $(p<0.016)$, whereas in radiation workers it was not of significant influence $(p=0.193)$.

Table 3. Poisson regression analysis of confounding factors on $\mathrm{MN}$ frequencies in peripheral lymphocytes of the study groups

\begin{tabular}{lccc}
\hline \multicolumn{1}{c}{ Confounding factors $^{\mathrm{a}}$} & IRR & $p$ & $95 \%$ CI \\
\hline All & & & \\
$\quad$ Gender (1,2) & 2.802 & $<0.0001$ & $2.727-2.876$ \\
Age (years) & 2.890 & $<0.0001$ & $2.428-3.352$ \\
Smoking status (1,2) & 0.337 & $<0.0001$ & $0.181-0.493$ \\
$\quad$ Years of exposure (years) & 3.367 & $<0.0001$ & $3.003-3.731$ \\
Controls & & & \\
$\quad$ Gender (1,2) & 2.451 & $<0.0001$ & $2.269-2.633$ \\
Age (years) & 2.565 & $<0.0001$ & $2.021-3.109$ \\
$\quad$ Smoking status (1,2) & 0.389 & 0.016 & $0.074-0.705$ \\
Radiation workers & & & \\
$\quad$ Gender (1,2) & 2.890 & $<0.0001$ & $2.809-2.972$ \\
Age (years) & 2.890 & $<0.0001$ & $2.428-3.352$ \\
Smoking status (1,2) & 0.123 & 0.193 & $-0.062-0.309$ \\
\hline
\end{tabular}

IRR: Incidence Rate Ratio

${ }^{\mathrm{a}}$ Gender: 1 , females; 2, males; smoking status: 1 , never; 2 , current.

\section{Genotype analysis}

The genotype distribution in this study was consistent with the Hardy-Weinberg equilibrium for all the SNPs studied, both in radiation workers and controls, as shown in Table 4. The frequencies of genotypes for radiation workers were CC $(45.68 \%)$, CT $(32.10 \%)$, and TT $(22.10 \%)$, with frequencies of alleles being $\mathrm{C}(61.73 \%)$ and $\mathrm{T}(38.27 \%)$. The frequencies of genotypes for controls were CC (45\%), CT (45\%), and TT (10\%), with frequencies of alleles being $\mathrm{C}(67.5 \%)$ and $\mathrm{T}(32.5 \%)$. The results of the $\chi^{2}$ test showed no significant difference in the same genotype between radiation workers and controls $(p>0.05)$.

Table 4. Genotype and allele frequencies of Arg194Trp in the study population.

\begin{tabular}{cccccc}
\hline & $\begin{array}{c}\mathrm{N} \\
(101)\end{array}$ & $\%$ & $\begin{array}{c}\text { Radiation } \\
\text { workers }(\mathrm{n}=81) \\
(\%)\end{array}$ & $\begin{array}{c}\text { Control } \\
(\mathrm{n}=20) \\
(\%)\end{array}$ & $\begin{array}{c}P \\
\text { value }\end{array}$ \\
\hline $\begin{array}{c}\text { Genotype } \\
\text { Codominant }\end{array}$ & & & & & \\
CC & 46 & 45.54 & $37(45.68)$ & $9(45.00)$ & \\
CT & 35 & 34.65 & $26(32.10)$ & $9(45.00)$ & 0.51 \\
TT & 20 & 19.81 & $18(22.22)$ & $2(10.00)$ & 0.34 \\
Allele & & & & & \\
C & & 62.87 & $100(61.73)$ & $27(67.5)$ & \\
T & & 37.13 & $62(38.27)$ & $13(32.5)$ & 0.5 \\
\hline
\end{tabular}

Note: $*$ the mean difference is significant at the 0.05 level

$\chi^{2}$ test was used for comparison of genotype distributions between radiation workers and controls 


\section{Links between MN frequencies and genotypes}

Distribution of MN frequencies by XRCC1 exon 6 genotypes, smoking status, and years of exposure are shown in Table 2. Among radiation workers, MN frequency was highest in the CT genotype group $(17.5 \pm 8.36)$ compared with TT $(17.22 \pm 7.08)$ and $\mathrm{CC}(13 \pm 7.03)$. In contrast, in the control group, MN frequency was highest in the wild-type CC $(11.33 \pm 5.38)$ compared with CT $(7.44 \pm 5.05)$ and TT $(5.5 \pm 6.36)$. This suggests an association between XRCC1 exon 6 gene polymorphism and DNA damage. A comparison of MN frequencies between radiation workers and controls, in the same genotype, showed that radiation workers had a higher MN frequency than controls. A significantly higher MN frequency was only found in radiation workers with CT genotype group compared to controls $(17.5 \pm 8.36$ versus $7.44 \pm 5.05 ; p=0.002$ ).

\section{DISCUSSION}

Various studies on the effects of high-dose ionizing radiation have been widely known, but the effects of low-dose ionizing radiation have not been widely studied. This is what drives the authors to conduct this research. The novelty of the research is the investigation of the biodosimetric marker of effects and susceptibility in individuals exposed to low-dose ionizing radiation, especially in hospital radiation workers in Indonesia. The association between SNPs in DNA repair genes and micronucleus frequencies are important to know, given that the $\mathrm{MN}$ frequency is one of the markers of cell damage at the DNA level.

The CBMN assay used in this study is a biomarker to evaluate the effects of ionizing radiation exposure, including in radiotherapy and occupations that are at risk of exposure to radiation as well as exposure to environmental radiation [15]. The radiation workers exposed to low-dose radiation exposure have a sensitivity to chromosomal damage. The results show that $\mathrm{MN}$ frequency was higher in radiation workers than in controls, although the difference was significant only in the non-smokers group and the CT genotype group. This is consistent with several previous studies suggesting that $\mathrm{MN}$ frequencies are higher in low-dose radiation workers than controls $[16,17]$.

The subjects used in this study never received exposure exceeding the permitted dose limit set by the Nuclear Energy Regulatory Agency of Indonesia for radiation workers ( $20 \mathrm{mSv}$ per year). The results of this study indicate a positive correlation between years of exposure and an increase in MN frequency of 0.07 per 1 year, but it is not significant $(p=0.689)$. This is similar to the study by Sakly et al. (2012) which found an increase of MN frequency in hospital radiation workers in Tunisia [18].

Poisson regression analysis showed that confounding factors, including gender and age, had a significant effect on DNA damage in the radiation workers and control. Smoking status had a significant effect only in controls whereas in radiation workers had no significant effect. The frequency of $\mathrm{MN}$ in non-smokers group is higher than in smokers, both in radiation workers and controls. This fact is consistent with the study by Narsesyan et al. which suggests that nicotine potentially protects cells against DNA-reactive carcinogens contained in cigarette smoke, although further study is needed through controlled intervention studies [19]. Bonassi et al. also stated that MN frequency did not increase in current smokers population, although interaction with occupational exposure is taken into account, except in heavy smokers (more than 30 cigarettes per day), while current smokers group in this study smoked fewer than 30 cigarettes per day [20]. This fact indicates that the negative effects of smoking should be studied more closely related to genetic factors and risks associated with chronic diseases, including cancer, resulting from low-level ionizing radiation exposure.

The frequency of MN increased significantly with age in the radiation workers and controls group $(p<0.0001)$. The studies conducted by Ramsey et al. and Bolognesi et al. showed that chromosome aberration measured in healthy organs lymphocytes increases with age and is a decisive factor in addition to environmental and genetic factors $[21,22]$. The increase in the $\mathrm{MN}$ frequencies with an increase in age and the effect of aging on the induction of chromosome damage rates was at least $25 \%$ [23]. Recent studies have shown that the increase in $\mathrm{MN}$ frequency was associated with increasing chromosomal instability in elderly people. The chromosome has a biphasic character, with the MN frequency increasing until 50 years old and decreasing with a further increasing age [24].

Poisson regression analysis in this study shows that MN frequency in females is higher than in males. The study conducted by Ishikawa et al. showed the opposite result. A higher MN frequency in males was probably due to the more fragile characteristics of the $\mathrm{Y}$ chromosome than the $\mathrm{X}$ chromosome [25]. The other studies have suggested that the MN frequency in women is higher than the mean $\mathrm{MN}$ frequency and will continue to increase for their entire lives. Such factors as age, gender, 
diet and lifestyle factors (e.g., exercise, alcohol, smoking and recreational drugs), either separately or in combination, have a significant effect on the frequency of MN [26,27]. The study conducted by Fenech (1998) suggests that age and gender are the most important variables affecting $\mathrm{MN}$ frequency with $\mathrm{MN}$ frequency in females being greater than in males (1.2-1.6) depending on age group [28].

Genotype analysis showed a clear association between XRCC1 exon 6 genotype polymorphisms and $\mathrm{MN}$ frequency. The highest $\mathrm{MN}$ rate in the radiation workers group was in all genotypes. The mean of MN frequency was significantly different only in the CT genotype. The frequency of CT genotype was highest compared to the other genotypes in the same group of radiation workers, indicating that individuals with heterozygous CT genotypes have an increased risk than radiation workers with the CC/wild-type genotype. This is consistent with research from Wang et al. (2010) in the Chinese population which states that the CT genotype was higher than the CC and TT genotypes [29]. Leng et al. (2005) also observed that Arg194Trp variant was associated with MN frequency [30].

A possible explanation is the XRCC1 exon 6 polymorphism located at the domain of XRCC1 localization signal adjacent to other domains that play a role in mediating the interaction between polymerase- $\beta$ and apurinic/apyridinic endonucleases. This SNP can disturb the XRCC1 conformation, resulting in a decreased protein affinity or decreased effectiveness of DNA repair.

\section{CONCLUSION}

In conclusion, our results show that radiation workers had a higher $\mathrm{MN}$ frequency than controls. The genetic polymorphism of XRCC1 gene exon 6 with a mutant heterozygous/CT variant demonstrated an association with the extent of DNA damage in the hospital radiation workers in this study. In the subsequent studies, it is necessary to examine the DNA repair genes polymorphism in populations with controlled non-genetic factors, such as lifestyle, environment, and exercise, that affect the MN frequency as a biomarker of DNA damage.

\section{ACKNOWLEDGMENT}

This study was fully supported by Center for Technology of Safety and Radiation Metrology, National Nuclear Energy Agency of Indonesia.

\section{REFERENCES}

1. N. Hamada and Y. Fujimichi, J. Radiat. Res. 55 (2014) 629.

2. M. Fenech and A.A. Morley, Mutat. Res. 147 (1985) 29.

3. M. Fenech, Nat. Protoc. 2 (2007) 1084.

4. W.P. Chang, B.F. Hwang, D. Wang et al., Lancet. 350 (1997) 330.

5. J.H. Hoeijmakers, Nature 411 (2001) 366.

6. C. Seedhouse, R. Bainton, M. Lewis et al., Blood 100 (2002) 3761.

7. D. Ratnasinghe, S.X. Yao, J.A. Tangrea et al., Cancer Epidemiol. Biomarkers Prev. 10 (2001) 119.

8. K.K. Divine, F.D. Gilliland, R.E. Crowell et al., Mutat. Res. 461 (2001) 273.

9. E.J. Duell, R.C. Millikan, G.S. Pittman et al., Cancer Epidemiol. Biomarkers Prev. 10 (2001) 217.

10. M.C. Stern, D.M. Umbach, R.M. Lunn et al., Cancer Epidemiol. Biomarkers Prev. 11 (2002) 939.

11. J. de Boer and J.H. Hoeijmakers, Carcinogenesis 21 (2000) 453.

12. L.H. Thompson and M.G. West, Mutat. Res. 459 (2000) 1.

13. B. Norjmaa, K. Tulgaa and T. Saitoh, J. Mol. Pathol. Epidemiol. 1 (2016) 1.

14. R.A. Ryu, K. Tae, H.J. Min et al., J. Korean. Med. Sci. 26 (2011) 991.

15. A. Vral, M. Fenech and H. Thierens, Mutagenesis 26 (2011) 11.

16. S. Angelini, R. Kumar, F. Carbone et al., Mutat. Res. 570 (2005) 105.

17. M.G. Andreassi, I. Foffa, S. Manfredi et al., Mutat. Res. 666 (2009) 57.

18. A. Sakly, J.F. Gaspar, E. Kerkeni et al., J. Toxicol. Environ. Health 75 (2012) 934.

19. A. Narsesyan. R. Muradyan, M. Kundi et al., Mutagenesis 26 (2011) 295.

20. S. Bonassi, M. Neri, C. Lando et al., Mutat. Res. 543 (2003) 155.

21. M.J. Ramsey, D.H. Moore, J.F. Briner et al., Mutat. Res. 338 (1995) 95. 
22. C. Bolognesi, A. Abbondandolo, R. Barale et al., Cancer Epidemiol. Biomarkers Prev. 6 (1997) 249.

23. M. Fenech, Ann. N.Y. Acad. Sci. 20 (1998) 23.

24. T. Orta and S. Gunebakan, Indian J. Hum. Genet. 18 (2012) 95.

25. H. Ishikawa, Y. Tian and T. Yamauchi, J. Occup. Health. 45 (2003) 179.
26. A. Wojda, E. Zietkiewicz and M. Witt. Mutagenesis 22 (2007) 195.

27. M. Fenech and S. Bonassi, Mutagenesis 26 (2011) 43.

28. M. Fenech. Mutat. Res. 404 (1998) 155.

29. Q. Wang, F. Ji, Y. Sun et al., Carcinogenesis 6 (2010) 1068.

30. S. Leng, J. Cheng, L. Zhang et al., Cancer Epidemiol. Biomarkers Prev. 14 (2005) 1295. 